\title{
Corrigendum: Economy of Effort or Maximum Rate of Information? Exploring Basic Principles of Articulatory Dynamics
}

\author{
$\mathrm{Yi} \mathrm{Xu}^{1 *}$ and Santitham Prom-on ${ }^{2}$ \\ ${ }^{1}$ Department of Speech, Hearing and Phonetic Sciences, University College London, London, United Kingdom, \\ ${ }^{2}$ Department of Computer Engineering, King Mongkut's University of Technology Thonburi, Bangkok, Thailand
}

Keywords: maximum rate of information, economy of effort, stiffness, peak velocity, target approximation

\section{OPEN ACCESS}

Approved by:

Pascal van Lieshout, University of Toronto, Canada

${ }^{*}$ Correspondence: YiXu

yi.xu@ucl.ac.uk

Specialty section: This article was submitted to Language Sciences, a section of the journal

Frontiers in Psychology

Received: 13 June 2020

Accepted: 24 June 2020

Published: 28 July 2020

Citation:

Xu Y and Prom-on S (2020) Corrigendum: Economy of Effort or

Maximum Rate of Information?

Exploring Basic Principles of

Articulatory Dynamics.

Front. Psychol. 11:1753.

doi: 10.3389/fpsyg.2020.01753

\section{A Corrigendum on}

Economy of Effort or Maximum Rate of Information? Exploring Basic Principles of Articulatory Dynamics

by Xu, Y., and Prom-on, S. (2019). Front. Psychol. 10:2469. doi: 10.3389/fpsyg.2019.02469

In the original article, there were two errors in Equation (5). The lower limit of the summation should be $i=0$ rather than $i=1$. The denominator in the fraction should be $(k-i)$ ! rather than $(N-k)$ !

A correction has been made to Equation (5). The corrected equation appears below.

$$
c_{k}= \begin{cases}y(0)-b, & k=0 \\ y^{k}(0)+c_{0} \lambda-m, & k=1 \\ \frac{1}{k !}\left(y^{k}(0)-\sum_{i=0}^{k-1} \frac{k !}{(k-i) !} c_{i}(-\lambda)^{k-i}\right), & k \geq 2\end{cases}
$$

The authors apologize for this error and state that this does not change the scientific conclusions of the article in any way. The original article has been updated.

Copyright (C) $2020 \mathrm{Xu}$ and Prom-on. This is an open-access article distributed under the terms of the Creative Commons Attribution License (CC BY). The use, distribution or reproduction in other forums is permitted, provided the original author(s) and the copyright owner(s) are credited and that the original publication in this journal is cited, in accordance with accepted academic practice. No use, distribution or reproduction is permitted which does not comply with these terms. 